\title{
Remifentanil repairs cartilage damage and reduces the degradation of cartilage matrix in post-traumatic osteoarthritis, and inhibits IL-1 $\beta$-induced apoptosis of articular chondrocytes via inhibition of PI3K/AKT/NF-KB phosphorylation
}

\author{
Hai Ke ${ }^{1 \# \wedge}$, Xiaping Mou ${ }^{2 \#}$, Qing Xia ${ }^{3}$ \\ ${ }^{1}$ Department of Anesthesiology, Beijing Hospital of Traditional Chinese Medicine, Capital Medical University, Beijing, China; ${ }^{2}$ Department of \\ Orthopedics, The People's Hospital of Jianyang, Jianyang, China; ${ }^{3}$ Department of Traumatic Orthopedics, No. 1 People's Hospital of Yancheng, \\ Yancheng, China \\ Contributions: (I) Conception and design: All authors; (II) Administrative support: All authors; (III) Provision of study materials or patients: H Ke; \\ (IV) Collection and assembly of data: All authors; (V) Data analysis and interpretation: All authors; (VI) Manuscript writing: All authors; (VII) Final \\ approval of manuscript: All authors. \\ \#These authors contributed equally to this work. \\ Correspondence to: Qing Xia. Department of Traumatic Orthopedics, No. 1 People’s Hospital of Yancheng, Yancheng, China. Email: xiaqing0518@126.com.
}

Background: Remifentanil (RFT) is an opioid analgesic with a unique pharmacokinetic profile, and plays an important role in the intra- and post-operative periods. Post-traumatic osteoarthritis (PTO) is a particular type of osteoarthritis (OA) that occurs secondary to a traumatic injury. In the present study, we investigated the effects of RFT both in vivo and in vitro.

Methods: In vivo, 50 Sprague Dawley (SD) rats (7 weeks old) were randomly divided into five groups. Four groups of rats received RFT $(0.2,0.5$, and $1 \mu \mathrm{g})$ or vehicle (PTO group), while the remaining group served as the control. A PTO model in rats was established using the Hulth method. The cartilage damage, articular cartilage formation, and the degradation of cartilage matrix were evaluated. The effects of RFT on cell proliferation, apoptosis, and nuclear factor (NF)- $\kappa \mathrm{B}$ phosphorylation were also examined.

Results: The results indicated that RFT improved cartilage damage, enhanced articular cartilage formation, and inhibited the degradation of cartilage matrix in PTO model rats. Compared with the control group, the protein levels of Osterix (OSX), Collagen type I alpha 1 (COL1A1), and osteocalcin (OC) were down-regulated in PTO model rats. RFT also inhibited the interleukin-1 $\beta$ (IL-1 $\beta$ )-induced apoptosis of chondrocytes in vitro. Furthermore, the phosphoinositide 3-kinase (PI3K)/protein kinase B (AKT)/NF- $\mathrm{BB}$ pathway was inhibited both in vitro and in vitro.

Conclusions: RFT has significant potential as a therapeutic intervention to ameliorate PTO and provides a foundation for further clinical studies.

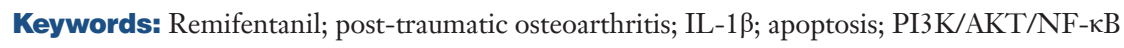

Submitted Aug 05, 2020. Accepted for publication Oct 24, 2020.

doi: $10.21037 /$ atm-20-6000

View this article at: http://dx.doi.org/10.21037/atm-20-6000

^ ORCID: 0000-0002-1014-9488. 


\section{Introduction}

Osteoarthritis (OA) is a clinical syndrome characterized by pain and disabling degeneration of joint tissues. It is a progressive disease that leads to long-term loss of mobility, loss of independence, and disability (1). Post-traumatic osteoarthritis (PTO) is a particular type of OA that occurs secondary to a traumatic injury (2). Approximately $12 \%$ of all OA cases may be attributable to a major joint injury (3). Following a joint injury, surgery is often required to restore function and relieve pain. However, evidence suggests that the OA occurs earlier in patients who have undergone joint surgery than in patients who have not had joint surgery (4). Considering that treatments are limited and there are presently no disease-modifying OA drugs (5), understanding the biological mechanisms is critical in developing more successful treatment options for PTO patients.

Remifentanil (RFT) is one of the most widely used opioid analgesics. It is a highly selective $\mu$-opioid receptor agonist with a strong sedative and analgesic effect (6). RFT is an ultra-short acting opioid that is rapidly degraded in the plasma and tissue by nonspecific esterases (7), and thus, has been used as an adjuvant analgesic for general anesthesia (8). It has also been shown to have a protective effect against hepatic ischemia-reperfusion injury (9). In human keratinocytes, RFT improves hydrogen peroxideinduced oxidative injury (10). Furthermore, it increases osteoblast differentiation in vitro by up-regulation of runt-related transcription factor 2 (RUNX2) and Osterix (OSX) expression. Therefore, RFT has the potential to assist with bone formation and healing (11). RFT also promotes the differentiation of pre-osteoclasts and induces maturation, including the increase in osteoclast size (12). Moreover, RFT preconditioning enhances cell viability and maturation of osteoblasts, and stimulates the expression of proteins including bone morphogenetic protein 2 (BMP-2), osteocalcin (OC), protein kinase B (AKT), type I collagen (CoL1A1), OSX, transforming growth factor (TGF)- $\beta 1$, hypoxia-inducible factor (HIF)- $1 \alpha$, and RUNX2 in osteoblasts (13). RFT exhibits minimal inhibitory effect on in vitro fresh human articular chondrocyte (hAC) proliferation (14).

In PTO, the initial injury leads to cartilage damage and the rapid death of chondrocytes. In the subsequent days, the increased degradation of cartilage matrix promotes further death of chondrocytes (15). AKT is a serine/ threonine protein kinase activated by extracellular factors through a phosphorylation mechanism dependent on phosphatidylinositol 3-kinase (PI3K) (16). The PI3K/ AKT pathway is reportedly involved in two key processes $(17,18)$. The degradation of cartilage is induced by matrix metalloproteinases (MMPs) and adamalysin with thrombospondin motif 5 (19). Activation of the PI3K/AKT pathway increases production of MMPs through a variety of downstream target proteins. Nuclear factor (NF)- $\kappa \mathrm{B}$ is one of the target proteins of the PI3K/AKT pathway and is also a key regulator of MMP production as a transcriptional factor (20). The PI3K/AKT pathway is also associated with tumor necrosis factor (TNF)- $\alpha$-induced activation of OA fibroblast-like synoviocytes, which may be involved in the pathogenesis of OA (21). Inhibition of the PI3K/AKT/ mammalian target of rapamycin (mTOR) signaling pathway can promote the autophagy of articular chondrocytes and attenuate the inflammatory response in rats with OA (22). Inhibition of the NF- $\kappa$ B signaling pathway affects the incidence and evolution of OA (23). Thus, the inhibition of PI3K/AKT pathway and NF- $\mathrm{KB}$ is considered to be an effective treatment for OA $(24,25)$. Allicin has been found to suppress interleukin (IL)- $1 \beta$-stimulated $\mathrm{PI} 3 \mathrm{~K} / \mathrm{AKT} / \mathrm{NF}-\kappa \mathrm{B}$ activation in chondrocytes (26), and Nobiletin dramatically suppresses the IL-1 $\beta$-stimulated phosphorylation of PI3K/AKT and activation of NF- $\mathrm{BB}$ in human OA chondrocytes (27). Therefore, evaluation of the $\mathrm{PI} 3 \mathrm{~K} / \mathrm{AKT} / \mathrm{NF}-\mathrm{\kappa B}$ pathway is important for the treatment of PTO.

In the present study, whether RFT plays a protective role in post-traumatic osteoarthritis has not been reported, the effects of RFT on cartilage damage, degradation of cartilage matrix in PTO model rats, and apoptosis of articular chondrocytes were investigated. Furthermore, the underlying mechanism PI3K/AKT/NF- $\mathrm{KB}$ pathway was also demonstrated.

We present the following article in accordance with the ARRIVE reporting checklist (available at http://dx.doi. org/10.21037/atm-20-6000).

\section{Methods}

\section{Animals}

Fifty Sprague Dawley (SD) rats (7 weeks old; approximately 230-250 g) were purchased from the Shanghai Laboratory Animal Center, Chinese Academy of Sciences (Shanghai, China). All animal experiments and protocols were performed in accordance with the National Institutes 
of Health (NIH) Guidelines for the Care and Use of Laboratory Animals. The Ethics Committee for Experimental Animal Management and Animal Welfare of Beijing Hospital of Traditional Chinese Medicine reviewed and approved the study. Code: No.20190419. Rats were acclimatized for 7 days with free access to water and standard rat nutrients. Before the experiments, the rats were kept in a room under the following conditions: temperature of $23 \pm 1{ }^{\circ} \mathrm{C}$; humidity level of $45-55 \%$; and a $12 \mathrm{~h}$ light/dark cycle.

\section{PTO model rats}

Of the 50 rats, 10 were randomly selected as the control group and the remaining 40 were selected as the PTO model group. The PTO model in rats was established using Hulth method $(28,29)$. Rats were anesthetized with a $10 \%$ volume fraction chloral hydrate $(300 \mathrm{mg} / \mathrm{kg})$. The right knee joints in PTO model group rats were then shaved, and a $2 \mathrm{~cm}$ incision was made on the medial side of the knee to expose the knee joint. The anterior cruciate ligament was then cut off and the medial meniscus was completely removed. Meanwhile, the articular cartilage surface was retained. The incision was rinsed with saline and closed layer-by-layer with 3-0 sutures. The rats in the control group underwent sham surgery, which involved cutting open the articular cavity without damaging the cruciate ligament or meniscus. Cefradine $500 \mathrm{mg}$ was injected intraperitoneally once daily for 3 consecutive days (at the same time each day). After surgery, all rats were allowed free exercise out of their cages for $30 \mathrm{~min}$ daily (at two separate intervals each day). After 6 weeks, the OA model was achieved.

\section{Administrations of RFT in the PTO model}

Rats in the PTO model group were randomly divided into four subgroups: a PTO model group, a PTO + RFT $0.2 \mu \mathrm{g}$ group, a PTO + RFT 0.5 $\mu$ group, and aPTO + RFT $1 \mu \mathrm{g}$ group ( $\mathrm{n}=10$ per group). Rats were intraperitoneally injected with RFT for 7 days at doses of $0.2,0.5$, and $1 \mu \mathrm{g} / \mathrm{kg}$ from the day the model was built. The control and PTO model groups were treated with equal volumes of saline once daily until the end of6 weeks. Bone damage, trabecular bone and articular cartilage formation, and cartilage matrix degradation were measured.

\section{Isolation and culture of chondrocytes}

The 7 weeks old SD rats were sacrificed and soaked in $75 \%$ ethanol for $20 \mathrm{~min}$. The articular cartilage was separated and cut up, and $1 \mathrm{~mL} 0.25 \%$ II collagenase type was added. The articular cartilage was then digested in a water bath at $37^{\circ} \mathrm{C}$ for 8 hours. When the articular cartilage was almost digested, the supernatant was removed after centrifugation. The cells were mixed with complete culture medium and cultured in an incubator with $5 \%$ carbon dioxide $\left(\mathrm{CO}_{2}\right)$. The chondrocytes were passaged when the density reached $90 \%$. All groups were pretreated with IL- $1 \beta$ for 24 h except for the control group. Chondrocyte experiments involved five groups: the control group, IL-1 $\beta$ group (complete medium with $10 \mathrm{ng} / \mathrm{mL}$ IL-1 $\beta$ ), RFT $50 \mathrm{ng} / \mathrm{mL}$ group (complete medium with $10 \mathrm{ng} / \mathrm{mL} \mathrm{IL-1 \beta}$ and $50 \mathrm{ng} / \mathrm{mL}$ RFT), RFT $100 \mathrm{ng} / \mathrm{mL}$ group (complete medium with $10 \mathrm{ng} / \mathrm{mL}$ IL $-1 \beta$ and $100 \mathrm{ng} / \mathrm{mL}$ RFT), and RFT $200 \mathrm{ng} / \mathrm{mL}$ group (complete medium with $10 \mathrm{ng} / \mathrm{mL}$ IL-1 $\beta$ and $200 \mathrm{ng} / \mathrm{mL} \mathrm{RFT)}$ ). After culturing for $24 \mathrm{~h}$, apoptosis and cartilage matrix degradation was measured. Insulinlike growth factor-1 (IGF-1) was PI3K agonist and were obtained from BiocodeHycel Company, Brussels, Belgium.

\section{Bone morphometry}

Rat femurs were dissected free of soft tissue, fixed in $4 \%$ paraformaldehyde for $24 \mathrm{~h}$, and scanned under microcomputed tomography $(\mu \mathrm{CT})$. The morphometry of trabecular bones was assessed by high-resolution Inveon microtomography (Siemens, Munich, Germany). Parameters included bone volume/total volume (BV/TV), trabecular bone surface/bone volume (BSA/BV), trabecular bone thickness (Tb.Th), trabecular bone number (Tb.N), and trabecular bone space (Tb.Sp).

\section{Histological examination}

Cartilage samples were fixed with $10 \%$ neutral buffered formalin. Samples were then decalcified in diethylpyrocarbonate treated $0.2 \mathrm{M}$ ethylenediaminetetraacetic acid (EDTA), embedded in paraffin wax, cut into sections (5 $\mu \mathrm{m}$-thick), and stained with hematoxylin and eosin (H\&E), Alcian blue, and Masson trichrome. Immunohistochemical staining was also performed to evaluate the level of NF- $\kappa$ Bp65.

\section{Western blot}

Eleven primary antibodies, including anti-OSX, antiCOL1A1, anti-OC, anti-MMP-1, anti-MMP-3, andanti- 
MMP-13, were purchased from Abcam (Cambridge, UK). After culturing for $48 \mathrm{~h}$, the isolated chondrocytes were lysed in radioimmunoprecipitation assay (RIPA) lysis buffer. The total protein concentration was determined using a bicinchoninic acid (BCA) kit (Pierce, Rockford, IL, USA). Equal amounts of protein were isolated by sodium dodecyl sulfate - polyacrylamide gel electrophoresis (SDS-PAGE) and transferred to polyvinylidene difluoride membranes (Bio-Rad, Hercules, CA). The membranes were blocked with $5 \%$ skim milk in Tris-buffered saline Tween (TBST) for $1 \mathrm{~h}$, and then incubated with primary antibody antiOSX (1:1,000, ab22552, Abcam), anti-COL1A1 (1:1,000, ab34710, Abcam), anti-OC (1:500, ab93876, Abcam), antiMMP-1 (1:1,000, ab137332, Abcam), anti-MMP-3 (1:500, ab53015, Abcam), and anti-MMP-13 (1:3,000, ab39012, Abcam) at $4{ }^{\circ} \mathrm{C}$ overnight. The membranes were then washed and subjected to goat anti-rabbit immunoglobulin (Ig)G horseradish peroxidase (HRP)-conjugated secondary antibodies. The blots were detected using an enhanced chemiluminescent (ECL) detection kit (Pierce, Rockford, IL, USA). Actin was used as a loading control. The band densities were determined and analyzed with an automatic digital gel image analysis system Bio-Rad CFX-96 (Bio-Rad, CA, USA).

\section{Cell counting Kit-8 (CCK-8) assay}

Chondrocytes were inoculated into 96-well plates at a concentration of $2 \times 10^{4}$ cells $/ \mathrm{mL}$ and cultured at $37{ }^{\circ} \mathrm{C}$. CCK-8 reagent (Beyotime Institute of Biotechnology, Haimen, China) was added into each well for $30 \mathrm{~min}$ at $37^{\circ} \mathrm{C}$ and absorbance values were read at $490 \mathrm{~nm}$.

\section{Flow cytometry}

A flow cytometry assay was performed using the annexin $\mathrm{V}$-propidium iodide (PI) apoptosis kit according to the manufacturer's instructions (Invitrogen, Carlsbad, CA, USA). Chondrocytes were seeded in 6-well plates $\left(1 \times 10^{6}\right.$ cells/well $)$ and cultured for 48 hours. The cells were then harvested by trypsinization and washed with cold phosphate-buffered saline (PBS), and then resuspended in binding buffer. Annexin V-fluorescein isothiocyanate (FITC) and PI were added to the suspension. The suspension was incubated for $15 \mathrm{~min}$ in the dark at room temperature, and then the binding buffer was added. Finally, the samples were analyzed by flow cytometry.

\section{BrdU staining}

The amount of 5'-bromo-2'-deoxyuridine (BrdU)was measured using the APC-BrdU Flow Kit (Cat Nr.552598, $\mathrm{BD}$ Pharmingen ${ }^{\mathrm{TM}}$ ) according to the manufacturer's instructions. The results were analyzed using the BD FACSDiva software.

\section{Statistical analyses}

All experimental data were presented as the mean \pm standard deviation (SD). SPSS Statistical analyses were performed using SPSS 22.0 software (SPSS Inc., Chicago, IL, USA). Comparisons between two groups were carried out using the Student's $t$-test. Differences between the groups were compared by one-way analysis of variance (ANOVA), and Duncan's method was used as a post-hoctest. Each experiment was performed independently at least in triplicate. Differences were considered statistically significant at $\mathrm{P}<0.05$.

\section{Results}

\section{RFT improved the bone damage induced by osteoarthritis}

Trabecular bone morphometry was performed to assess the bone damage caused by osteoarthritis. As shown in Figure 1, osteoarthritis significantly reduced the BV/TV, Tb.Th, and Tb.N values, and increased the BSA/BVand Tb. Sp values compared to the control group. Also, the BV/TV, Tb.Th, and Tb.N in PTO rats treated with 0.5 or $1 \mu \mathrm{g}$ RFT were increased compared to the PTO model group. Meanwhile, the BSA/BV and Tb.Sp were restored by 0.5 or $1 \mu \mathrm{g}$ RFT in PTO rats. However, there were no significant differences between the PTO + RFT $0.2 \mu g$ group and the PTO model group. Taken together, RFT was found to improve osteoarthritisinduced bone damage in a dose-dependent manner.

\section{RFT enhanced trabecular bone and articular cartilage formation in PTO rats}

The results of H\&E, Masson, and Alcian staining are shown in Figure $2 A$. According to these results, severe cartilage loss was observed in the PTO model group; the chondrocytes showed hyperplasia and disorder compared to control group. However, in PTO rats treated with 0.5 and $1 \mu \mathrm{g}$ RFT, the cartilage loss was restored and the chondrocytes were arranged in neat rows; cartilage structure was clear and with a smooth surface. The contents of trabecular 
A

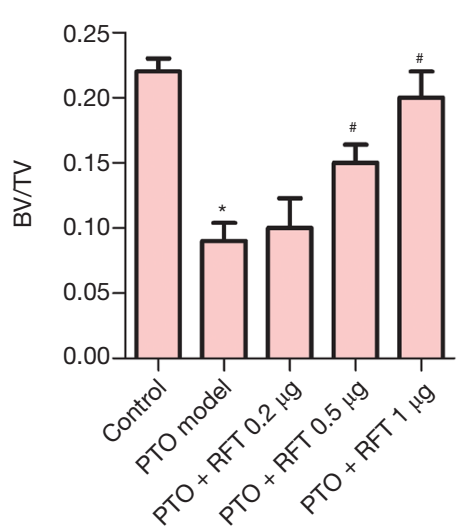

C

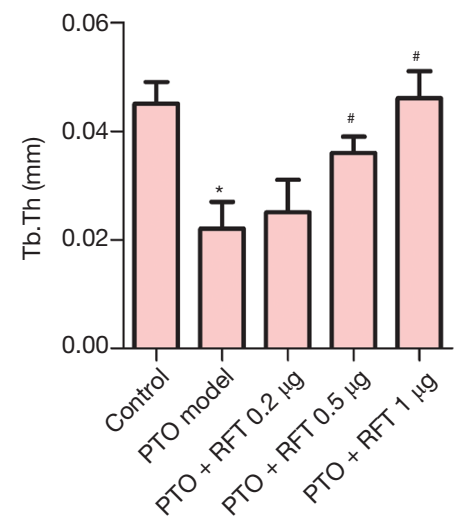

B

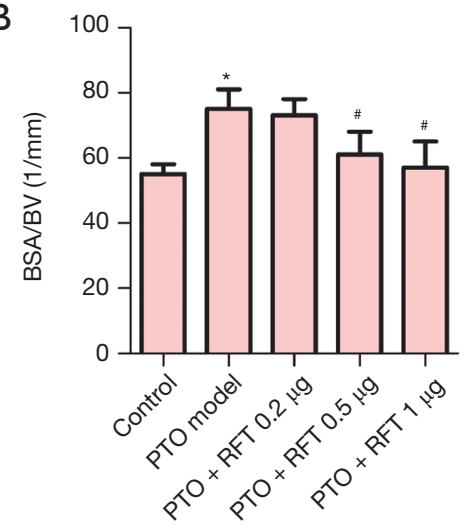

D

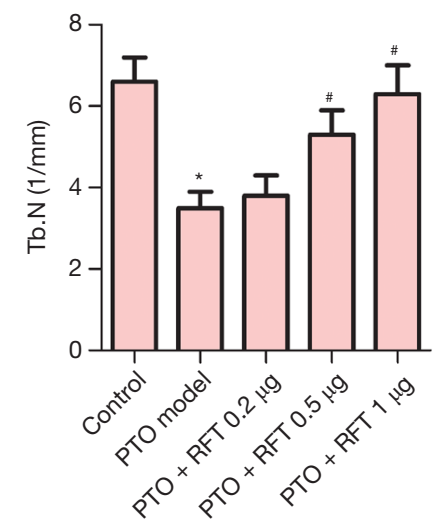

$\mathrm{E}$

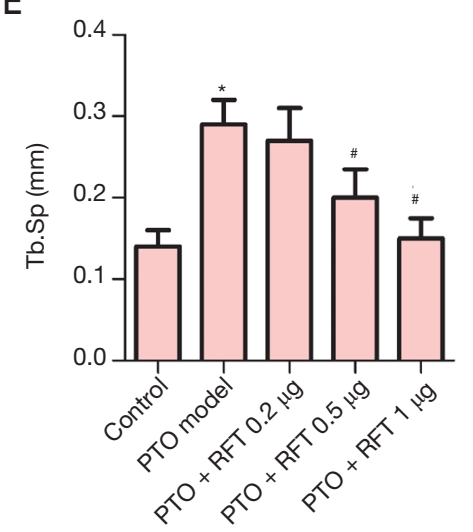

Figure 1 Remifentanil (RFT) improved the bone damage induced by osteoarthritis. The statistical analysis of BV/TV (A), BSA/BV (B), Tb.Th (C), Tb. N (D), and Tb. Sp (E). Compared with the control group, ${ }^{*}, \mathrm{P}<0.05$; compared with the post-traumatic osteoarthritis (PTO) model group, ${ }^{*}, \mathrm{P}<0.05$.

bone (Figure 2B) and cartilage (Figure 2C) were markedly decreased by osteoarthritis compared to the control group, but were increased by 0.5 and $1 \mu \mathrm{g}$ RTF compared to the PTO model group. The expression levels of OSX, CoL1A1, and OC were detected by western blot (Figure 2D,E). In the PTO model group, the expression levels of OSX, CoL1A1, and OC were markedly inhibited compared to the control group. In the PTO + RFT $0.5 \mu \mathrm{g}$ and PTO + RFT $1 \mu \mathrm{g}$ groups, the levels of OSX, CoL1A1, and OC were upregulated compared to the PTO model group. In summary, RFT enhanced trabecular bone and articular cartilage formation in PTO rats in a dose-dependent manner.

\section{RFT alleviated the degradation of cartilage matrix by inhibiting the phosphorylation of PI3K/AKT/NF- $\mathrm{KB}$ p65in PTO rats}

MMPs can degrade almost all cartilage matrix, and thus, they can be used as markers of matrix degradation. The levels of MMP-1, MMP-3, and MMP-13 were detected by western blot (Figure $3 A$ ), and were found to be greatly increased in the PTO model group compared to the control group. The levels of MMP-1 and MMP-3 were notably reduced by 0.5 and $1 \mu \mathrm{g}$ RFT in PTO rats, and the level of MMP-13 was reduced by all doses of RFT. The phosphorylation of PI3K, AKT, and NF- $\mathrm{KBp} 65$ was also measured by western blot (Figure 3B). The expression of phosphorylated PI3K (p-PI3K)/PI3K was up-regulated in the PTO model group compared to the control group and was down-regulated by 0.5 and $1 \mu \mathrm{g}$ RFT compared to the PTO model group. The expressions of phosphorylated AKT (p-AKT)/AKT and phosphorylated p65 (p-p65)/p65 were also decreased by RFT compared to the PTO model group. Immunohistochemical staining was performed to

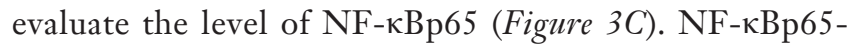
positive cells dramatically increased in the PTO model 
A

\begin{tabular}{|llllll|}
\hline PTO & - & + & + & + & + \\
RFT & 0 & 0 & 0.2 & 0.5 & $1 \mu \mathrm{g}$ \\
\hline
\end{tabular}

$\nsubseteq$
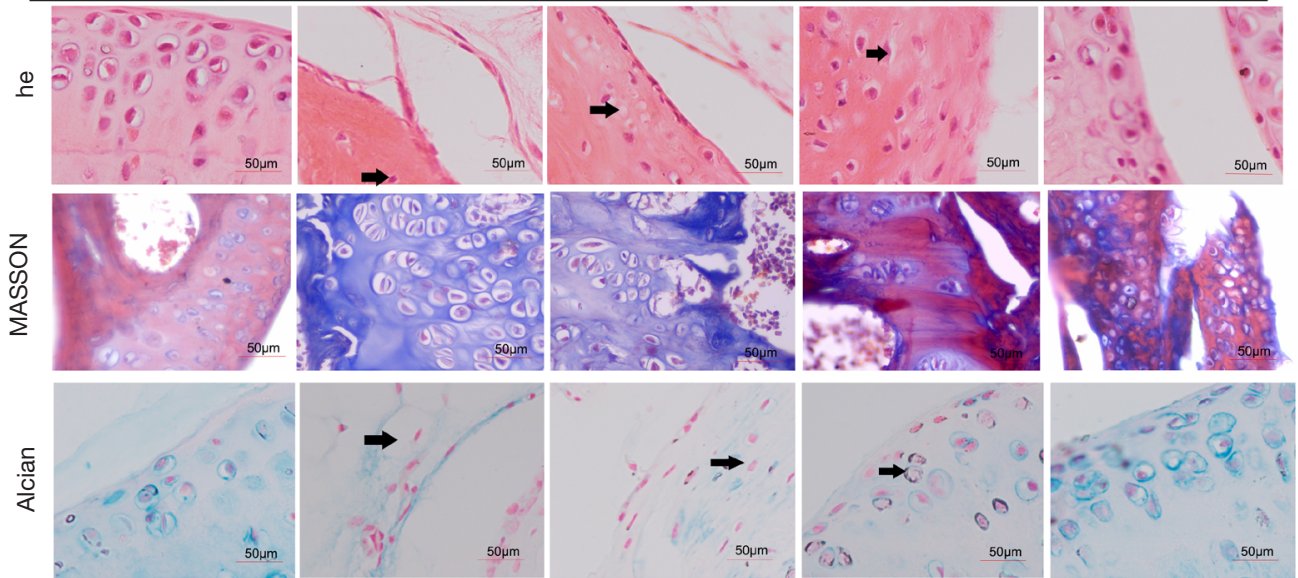

B

C
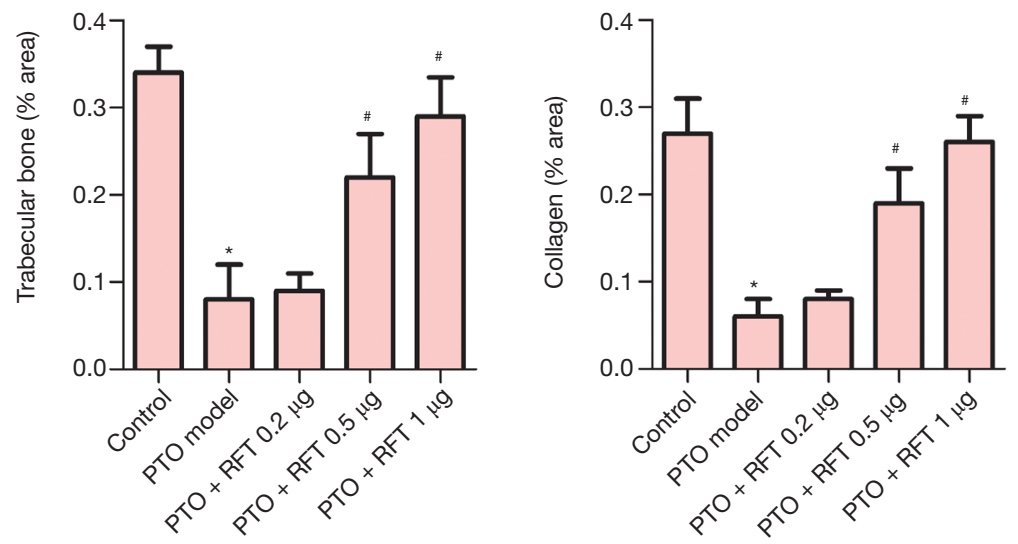

D

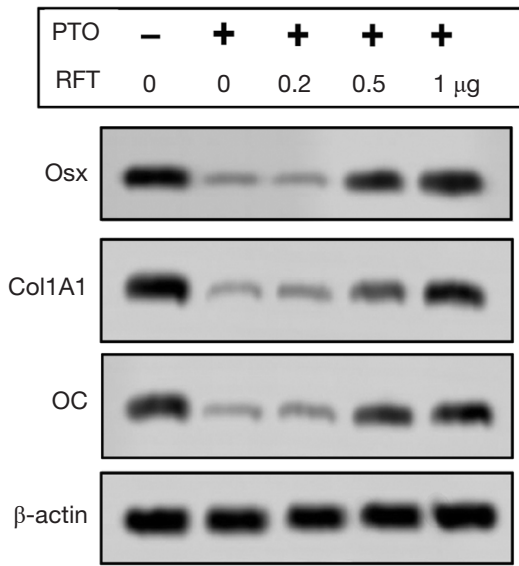

E

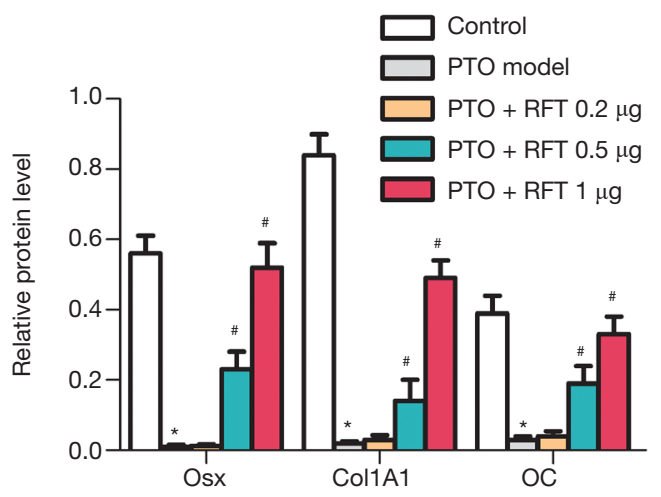

Figure 2 Remifentanil (RFT) enhanced trabecular bone and articular cartilage formation in post-traumatic osteoarthritis (PTO) rats. (A) The results of H\&E, Masson, and Alcian staining. The relative area of trabecular bone (B) and collagen (C) were analyzed using Image J software. (D) The expressions of osterix (OSX), collagen type I alpha 1 (COL1A1), and osteocalcin (OC) detected by western blot. (E) The protein levels of OSX, CoL1A1, and OC. Compared with the control group, *, $\mathrm{P}<0.05$; compared with the PTO model group, ${ }^{*}, \mathrm{P}<0.05$. 
A
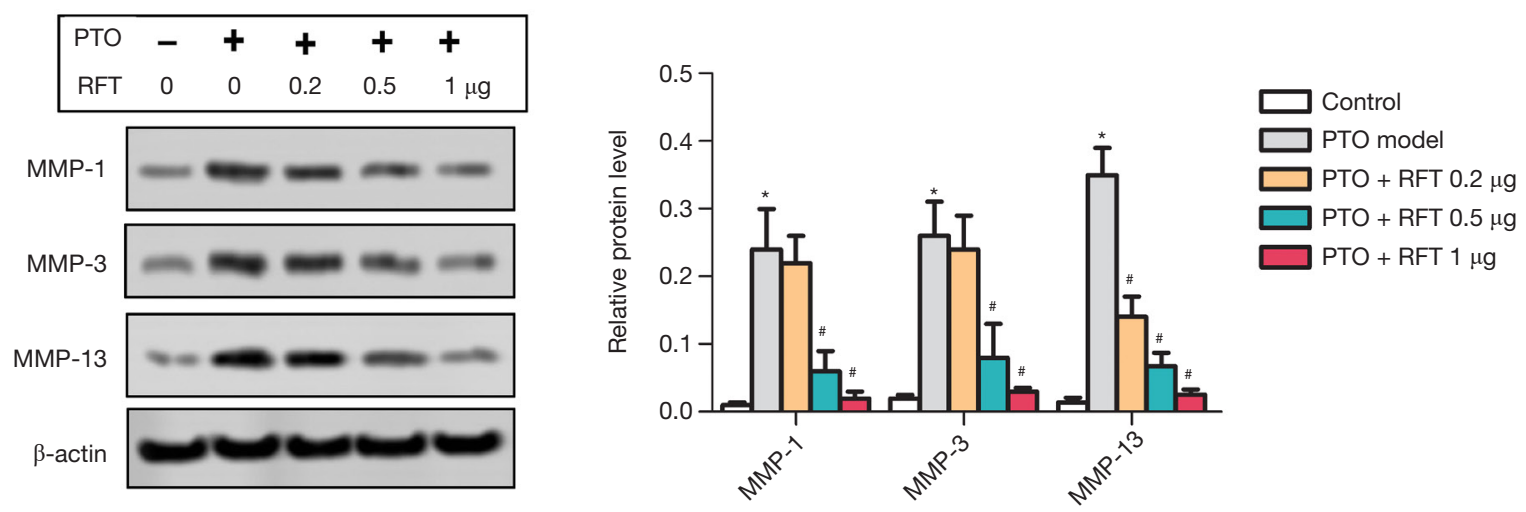

B
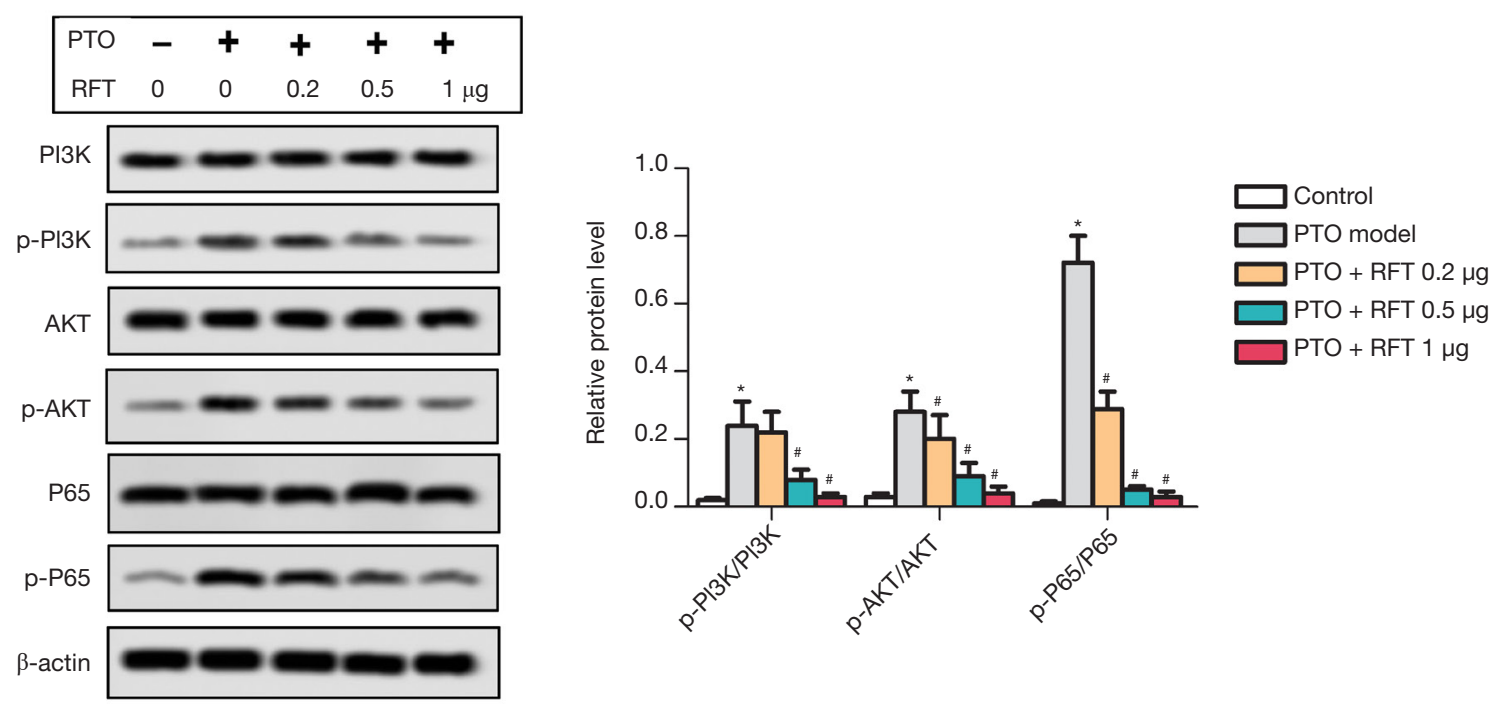

C
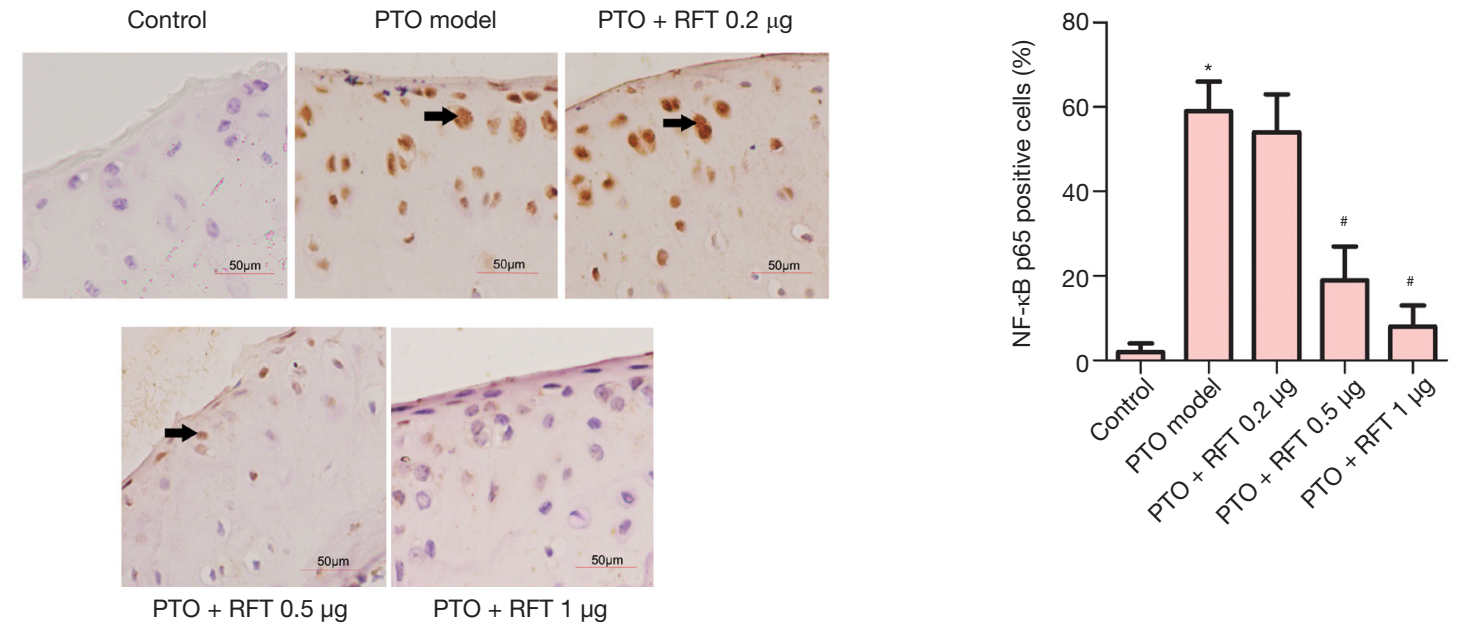

Figure 3 Remifentanil (RFT) alleviated the degradation of cartilage matrix by inhibiting the phosphorylation of PI3K/AKT/NF-kBp65 in post-traumatic osteoarthritis (PTO) rats. (A) The expressions of MMP-1, MMP-3, and MMP-13 were measured by western blot. (B) The

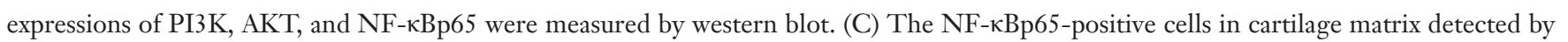
immunohistochemical staining. Compared with the control group, *, $\mathrm{P}<0.05$; compared with the PTO model group, ${ }^{\text {* }}, \mathrm{P}<0.05$. 
group compared to the control group and were reduced in the PTO + RFT $0.5 \mu \mathrm{g}$ and PTO + RFT $1 \mu \mathrm{g}$ groups compared to the PTO model group. In short, RFT alleviated the degradation cartilage matrix in PTO rats.

\section{RFT inbibited IL-1ß induced apoptosis in rats' articular chondrocytes}

The toxicity of RFT to articular chondrocytes was evaluated by cell viability (Figure 4A). A RFT concentration of $500 \mathrm{ng} / \mathrm{mL}$ or higher had a significant impact on cell viability, and so, 50, 100, and $200 \mathrm{ng} / \mathrm{mL}$ were chosen in the subsequent experiments. The result of BrdU staining showed that IL- $1 \beta$ reduced BrdU-positive cells compared to the control group, while RFT increased BrdUpositive cells in a dose-dependent manner compared to the IL-1 $\beta$ group (Figure $4 B$ ). The statistical analysis of BrdU-positive cells was consistent with the above result (Figure $4 C$ ). Apoptosis was assessed by flow cytometry assay (Figure 4D). The cell apoptosis rate was substantially increased by IL- $1 \beta$ compared to the control group, however was significantly reduced by RFT compared to the IL- $1 \beta$ group (Figure 4E). The proliferation-related protein Ki67 and apoptosis-related protein caspase- 3 were measured by western blot (Figure $4 F$ ). The expression of Ki67 was notably inhibited by IL-1 $\beta$, however it was considerably increased by RFT. The ratio of cleaved caspase- 3 to caspase- 3 was promoted by IL- $1 \beta$ and then decreased by RFT. These results indicated that RFT inhibited IL-1 $\beta$ induced apoptosis in the rats' articular chondrocytes in a dose-dependent manner.

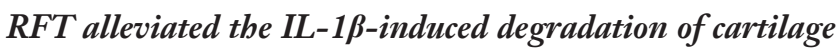 matrix by inhibiting the phosphorylation of PI3K/AKT/ NF-кBp65}

The expressions of MMPs and PI3K/AKT/NF- $\mathrm{kBp} 65$ are shown in Figure $5 A$ and Figure $5 B$, respectively. In the rats' articular chondrocytes, the expressions of MMP-1, MMP3 , and MMP-13 were highly increased by IL- $1 \beta$ compared to the control group, however were reduced by RFT compared to the IL-1 $\beta$ group (Figure $5 A$ ). The changes in p-PI3K/PI3K, p-AKT/AKT, and p-p65/p65 were similar to MMP-1, MMP-3, and MMP-13 (Figure 5B). The levels of $\mathrm{p}-\mathrm{PI} 3 \mathrm{~K} / \mathrm{PI} 3 \mathrm{~K}$ and $\mathrm{p}-\mathrm{AKT} / \mathrm{AKT}$ were increased in IGF1 group compared with IL-1 $\beta$ group. Importantly, the levels of $\mathrm{p}-\mathrm{PI} 3 \mathrm{~K} / \mathrm{PI} 3 \mathrm{~K}$ and $\mathrm{p}-\mathrm{AKT} / \mathrm{AKT}$ were increased in IGF-1 + RFT $200 \mathrm{ng} / \mathrm{mL}$ group compared with IGF1 group (Figure 5C). Put simply, RFT alleviated the IL-1 $\beta$ induced degradation of cartilage matrix by inhibiting the phosphorylation of PI3K/AKT/NF-кBp65 and nuclear translocation of NF- $\kappa \mathrm{Bp} 65$.

\section{Discussion}

PTO is a common condition caused by trauma and is disabling in patients who have sustained certain injuries (3). Since PTO typically arises from an injury to the joint, an opportunity exists for early therapeutic, and even prophylactic intervention (30). In this study, RFT was used as a treatment for PTO in rats. The effects of RFT on PTO and the underlying mechanisms were investigated.

In the past, changes in articular cartilage were considered to be the major pathological changes in OA. However, recent studies have revealed that all joint structures including subchondral and trabecular bones will also be affected (31). The BV/TV value reflects the distribution density of trabecular bone and is an important index used to evaluate trabecular bone microstructure. The BV/TV, Tb.Th, and Tb.N values were increased by RFT, and the BSA/BV and Tb.Sp were decreased by RFT.

PTO reduces the content of cartilage and trabecular bone. OSX is a necessary osteoblast-specific transcription factor for bone formation, and regulates the differentiation and proliferation of osteoblasts (32). It is located at chromosome 12q13.13 near the Sp gene. CoL1A1 is an important marker of osteoblast differentiation; studies have shown that the expression of CoL1A1 is closely related to OSX (33). OC is the main non-collagen protein in bone with a molecular weight of $5.8 \mathrm{kD}(34)$. It is a marker of mature osteoblasts and is thought to regulate bone matrix formation (35). The level of OC can directly represent the activity of osteoblasts. Thus, OSX, CoL1A1, and OC are important factors of trabecular bone and articular cartilage formation. In the present study, the expressions of OSX, CoL1A1, and OC were decreased by PTO but increased by RFT in PTO rats. This result indicates that RFT enhances articular cartilage formation by up-regulating the expression of bone formation-related proteins.

MMP is the major enzyme involved in the degeneration of articular cartilage in OA. Articular cartilage consists of chondrocytes and cartilage matrix, and its degeneration typically involves apoptosis of chondrocytes and degradation of cartilage matrix. The main components of cartilage matrix are aggrecan and type II collagen (36). 
A

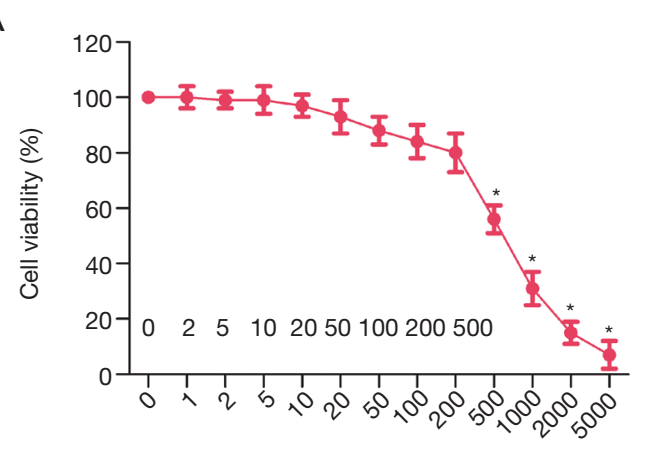

Concentratiǫo(ng/ML)
C

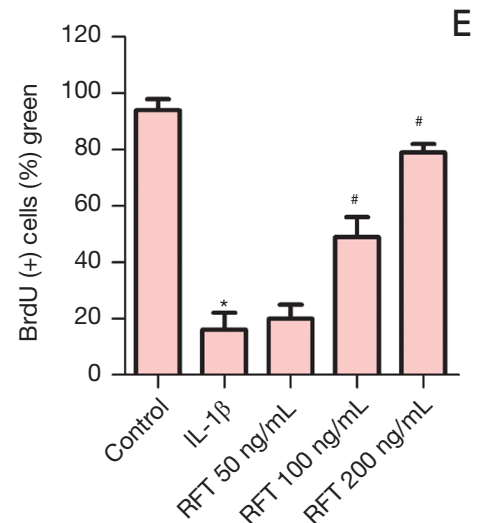

E

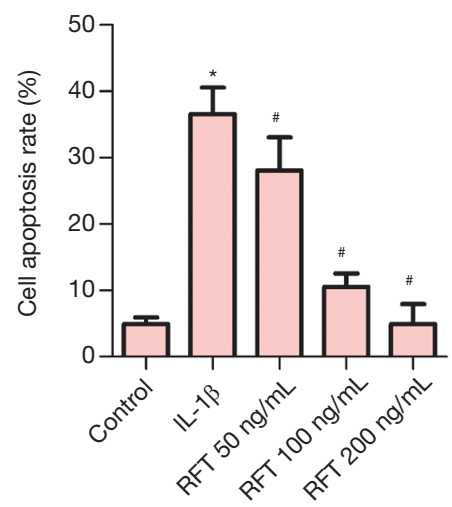

B

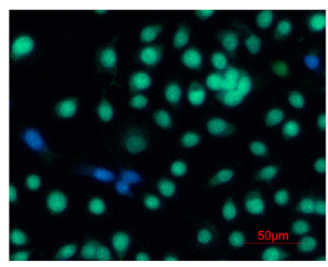

D

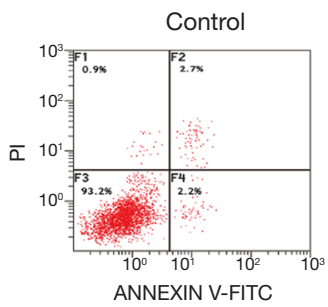

$\mathrm{F}$

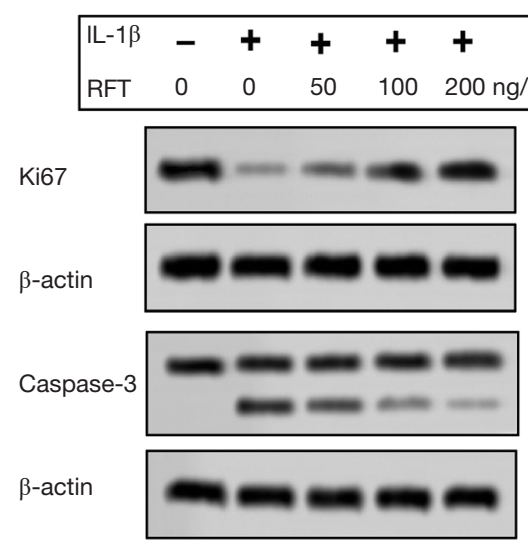

IL-1 $\beta$

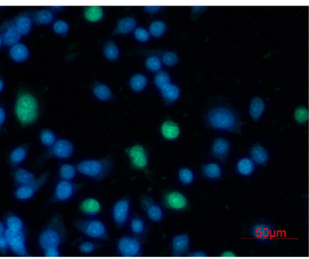

IL-1 $\beta$
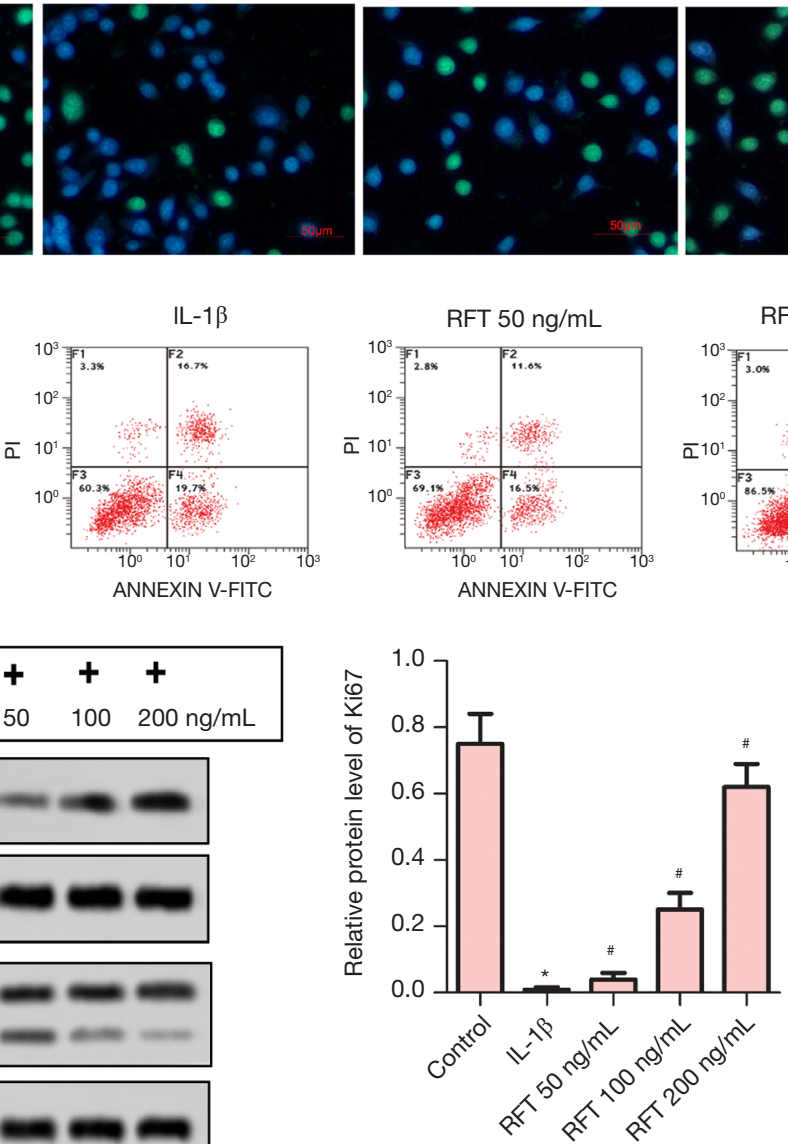

RFT $100 \mathrm{ng} / \mathrm{mL}$

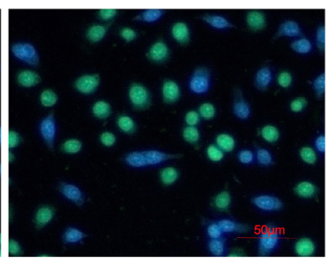

$\mathrm{RFT} 100 \mathrm{ng} / \mathrm{mL}$

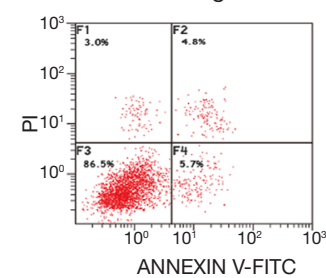

RFT $200 \mathrm{ng} / \mathrm{mL}$
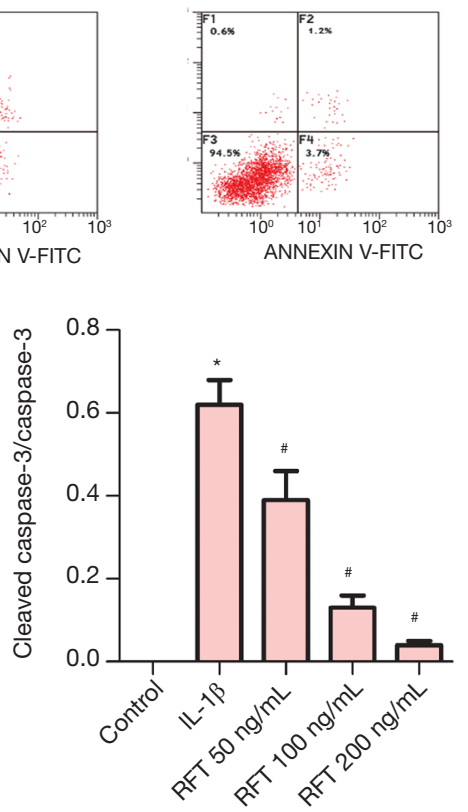

Figure 4 Remifentanil (RFT) inhibited IL-1 $\beta$-induced apoptosis in rats' articular chondrocytes. (A) Toxicity of RFT to cells performed by CCK8. The result of BrdU staining (B) and the statistical analysis of BrdU-positive cells (C). The result of flow cytometry assay (D) and the statistical analysis of cell apoptosis rate (E). (F) The protein levels of Ki67 and caspase-3 detected by western blot. Compared with the control group, ${ }^{*}, \mathrm{P}<0.05$; compared with the IL- $1 \beta$-induced group, ${ }^{*}, \mathrm{P}<0.05$. 
A
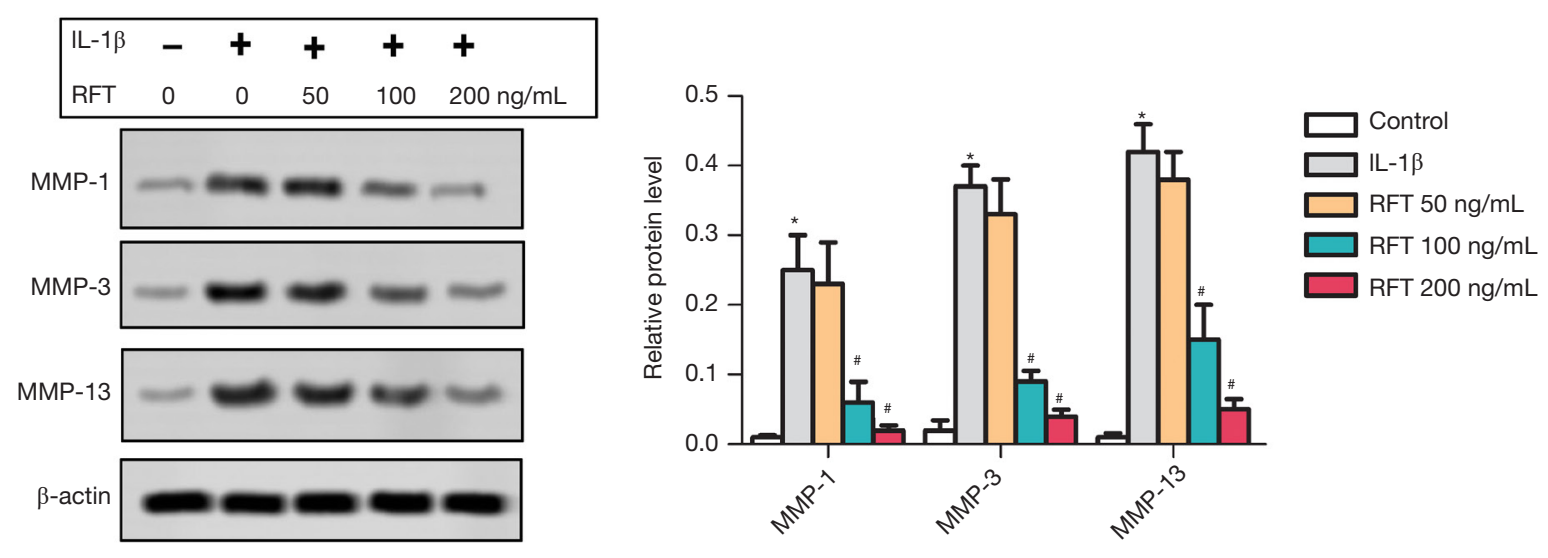

B
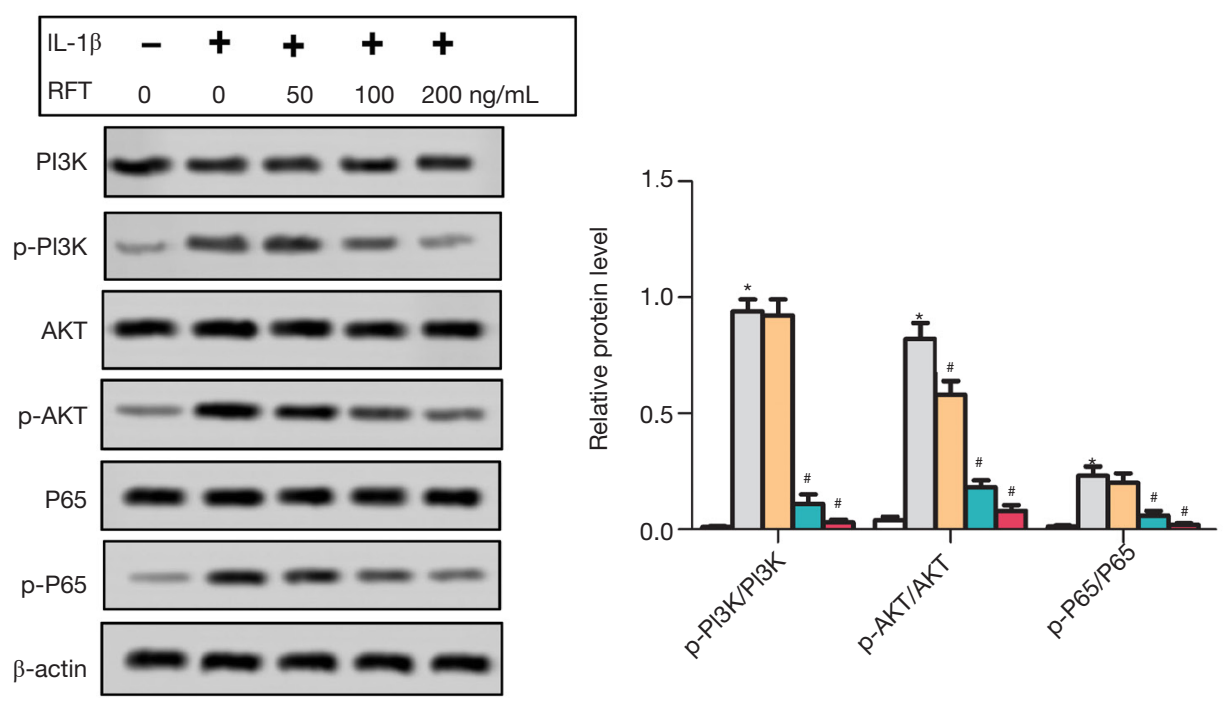

C
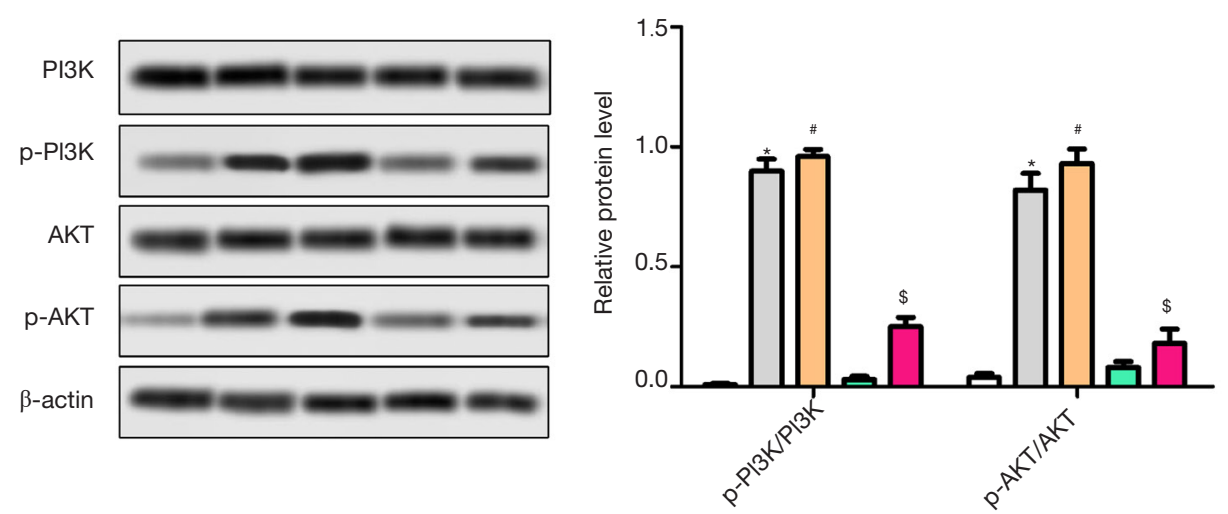

Figure 5 Remifentanil (RFT) alleviated the IL-1 $\beta$-induced degradation of cartilage matrix by inhibiting the phosphorylation of PI3K/AKT/ NF-кBp65. (A) The expressions of MMP-1, MMP-3, and MMP-13 were measured by western blot. (B) The expressions of PI3K, AKT, and NF- $\kappa$ Bp65 were measured by western blot. (C) The expressions of PI3K and AKT were measured by western blot. Compared with the control group, *, $\mathrm{P}<0.05$; compared with the IL-1 $\beta$-induced group, ${ }^{*}, \mathrm{P}<0.05$; compared with the RFT $200 \mathrm{ng} / \mathrm{mL}$ group, ${ }^{\$}, \mathrm{P}<0.05$. 
Many MMPs have been found to be increased in OA (37). In the MMP family, MMP-1, MMP-3, and MMP-13 are considered to be the most important in the degeneration of the articular cartilage (38). MMP-1 is one of the principal proteases capable of degrading the bone matrix (39). MMP-13 degrades aggrecan and preferentially digests type II collagen (40). MMP-3 can digest aggrecan and activate other proMMPs including proMMP-13 (41). The intracellular signaling pathway PI3K/AKT has also been shown to be related to the degradation of cartilage matrix. Several studies have reported that the expression of MMPs could be changed via the PI3K/AKT pathway (42). NF$\kappa \mathrm{B}$ is a downstream protein of the PI3K/AKT pathway and can regulate the secretion of MMP (20), with inhibition of $\mathrm{NF}-\kappa \mathrm{B}$ reducing the secretion of MMP (43). The p-PI3K and $\mathrm{p}-\mathrm{AKT}$ are phosphorylated activated forms of PI3K

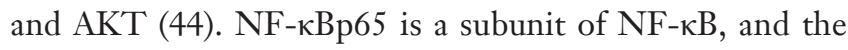
expression of p-p65 signifies that $\mathrm{NF}-\kappa \mathrm{Bp} 65$ has been activated (45). In this study, the levels of p-PI3K/ PI3K, $\mathrm{p}-\mathrm{AKT} / \mathrm{AKT}$, and p-p65/p65 were up-regulated by PTO and down-regulated by RFT. Our finding shows that RFT could alleviate the degradation of cartilage matrix by inhibiting the phosphorylation of PI3K/AKT/NF-кBp65 in PTO rats.

IL- $1 \beta$ is a typical inflammatory cytokine; normal chondrocytes cultured in vitro produce trace amounts of IL$1 \beta$. High concentrations of IL- $1 \beta$ stimulate the secretion of MMP, leading to the degradation of cartilage matrix (46). IL-1 $\beta$ can also stimulate chondrocytes to produce nitric oxide, inhibit the proliferation of chondrocytes, and induce the apoptosis of articular chondrocytes (47). Ki67 is a nuclear antigen present in proliferating cells, and is thus an intrinsic marker of cell proliferation (48). Caspase proteins regulate almost all apoptosis-related signaling pathways, in which caspase- 3 plays a key role. Cleaved caspase- 3 is the active form of caspase-3, and is necessary for many apoptotic nuclear changes (49). So, the increased Ki67 and decreased cleaved caspase-3/caspase-3 indicates enhanced cell proliferation and reduced apoptosis. In this study, the results of BrdU staining and flow cytometry assay revealed greater cell proliferation and decreased apoptosis following treatment with RFT. Taken together, RFT enhances cell proliferation and inhibitsIL- $1 \beta$-induced apoptosis in articular chondrocytes.

The degradation of cartilage matrix in vitro was also assessed. Changes in the expression of MMP-1, MMP-3, MMP-13, p-PI3K/PI3K, p-AKT/AKT, and p-p65/p65 were consistent with those in PTO rats. NF- $\mathrm{\kappa B}$ is a transcription factor widely found in the cytoplasm that remains inactive when cells are motionless (50). The nuclear translocation

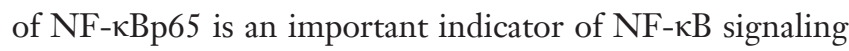
pathway activation (51), and confirms that gene expression of many cytokines involved in the inflammatory response process of $\mathrm{OA}$ were activated by the $\mathrm{NF}-\kappa \mathrm{B}$ signaling pathway. Once activated, NF- $\kappa$ Bp65 mediates various inflammatory factors and enzymes that lead to apoptosis and dysfunction of chondrocytes (52). In the research, the expressions of MMP-1, MMP-3, MMP-13, p-PI3K/PI3K, $\mathrm{p}-\mathrm{AKT} / \mathrm{AKT}$, and p-p65/p65 were highly increased by IL$1 \beta$ compared to the control group, however were reduced by RFT compared to the IL- $1 \beta$ group.

Hyperglycemia-induced oxidative stress abrogates remifentanil preconditioning (RPC) cardioprotection by impairing Cav-3-modulated PI3K/Akt and JAK2/STAT3 signaling. Antioxidant treatment with $\mathrm{N}$-acetylcysteine (NAC) restores RPC-induced cardioprotection in diabetes by improving Cav-3-dependent Akt and STAT3 activation and by facilitating the cross talk between PI3K/Akt and JAK2/STAT3 signaling pathways (53). RTF protects adult rat cardiomyocytes from hypoxiareoxygenation injury and its effects appears to be dependent on the $\delta$-opioid receptor mediated activation of PI3K/ Akt and subsequent extracellular signal-regulated kinase (ERK) signaling pathways (54). RTF postconditioning improves global cerebral ischemia-induced spatial learning and memory deficit in rats via inhibition of neuronal apoptosis through the PI3K signaling pathway (55). RTF attenuates lipopolysaccharide-induced acute lung injury by downregulating the NF- $\kappa \mathrm{B}$ signaling pathway (56). RTF reduces LPS-induced inflammatory response through PARP-1/NF- $\kappa \mathrm{B}$ signaling pathway in human aortic endothelial cells (HAECs) (57). In this research, RFT alleviated PTO injury by inhibiting the phosphorylation of $\mathrm{PI} 3 \mathrm{~K} / \mathrm{AKT} / \mathrm{NF}-\mathrm{kB} \mathrm{p} 65$ in vivo and in vitro.

In the present study, we investigated the effects of RFT on cartilage damage and degradation of cartilage matrix in PTO model rats. The in vitro effects of RFT on IL$1 \beta$-induced apoptosis and degradation of cartilage matrix were also demonstrated. RFT was found to repair cartilage damage and the reduce degradation of cartilage matrix in PTO in rats, and inhibit apoptosis in IL- $1 \beta$-induced rats' articular chondrocytes via inhibition of PI3K/AKT/NF- $\mathrm{KB}$ phosphorylation. This study provides a promising approach for the treatment of PTO. However, more studies in this 
area are needed to further investigate the protective effects of RFT in clinical application.

\section{Acknowledgments}

Funding: None.

\section{Footnote}

Reporting Checklist: The authors have completed the ARRIVE reporting checklist. Available at http://dx.doi. org/10.21037/atm-20-6000

Data Sharing Statement: Available at http://dx.doi. org/10.21037/atm-20-6000

Conflicts of Interest: All authors have completed the ICMJE uniform disclosure form (available at http://dx.doi. org/10.21037/atm-20-6000). The authors have no conflicts of interest to declare.

Ethical Statement: The authors are accountable for all aspects of the work in ensuring that questions related to the accuracy or integrity of any part of the work are appropriately investigated and resolved. All animal experiments and protocols were performed in accordance with the National Institutes of Health (NIH) Guidelines for the Care and Use of Laboratory Animals. The Committee for Animal Experiments of Beijing Hospital of Traditional Chinese Medicine approved all of the experiments involving animals. Code: No.20190419.

Open Access Statement: This is an Open Access article distributed in accordance with the Creative Commons Attribution-NonCommercial-NoDerivs 4.0 International License (CC BY-NC-ND 4.0), which permits the noncommercial replication and distribution of the article with the strict proviso that no changes or edits are made and the original work is properly cited (including links to both the formal publication through the relevant DOI and the license). See: https://creativecommons.org/licenses/by-nc-nd/4.0/.

\section{References}

1. WHO Scientific Group on the Burden of Musculoskeletal Conditions at the Start of the New Millennium. The burden of musculoskeletal conditions at the start of the new millennium. World Health Organ Tech Rep Ser. 2003;919:i-x, 1-218, back cover.

2. Carbone A, Rodeo S. Review of current understanding of post-traumatic osteoarthritis resulting from sports injuries. J Orthop Res 2017;35:397-405.

3. Brown TD, Johnston RC, Saltzman CL, et al.

Posttraumatic osteoarthritis: a first estimate of incidence, prevalence, and burden of disease. J Orthop Trauma 2006;20:739-44.

4. Brophy RH, Gray BL, Nunley RM, et al. Total knee arthroplasty after previous knee surgery: expected interval and the effect on patient age. J Bone Joint Surg Am 2014;96:801-5.

5. Rai MF, Duan X, Quirk JD, et al. Post-Traumatic Osteoarthritis in Mice Following Mechanical Injury to the Synovial Joint. Sci Rep 2017;7:45223.

6. Glass PS, Gan TJ, Howell S. A review of the pharmacokinetics and pharmacodynamics of remifentanil. Anesth Analg 1999;89:S7-14.

7. Westmoreland CL, Hoke JF, Sebel PS, et al. Pharmacokinetics of remifentanil (GI87084B) and its major metabolite (GI90291) in patients undergoing elective inpatient surgery. Anesthesiology 1993;79:893-903.

8. Komatsu R, Turan AM, Orhan-Sungur M, et al. Remifentanil for general anaesthesia: a systematic review. Anaesthesia 2007;62:1266-80.

9. Cui C, Yu F, Yin S, et al. Remifentanil Preconditioning Attenuates Hepatic Ischemia-Reperfusion Injury in Rats via Neuronal Activation in Dorsal Vagal Complex. Mediators Inflamm 2018;2018:3260256.

10. Kim CH, Jeong SS, Yoon JY, et al. Remifentanil reduced the effects of hydrogen peroxide-induced oxidative stress in human keratinocytes via autophagy. Connect Tissue Res 2017;58:597-605.

11. Yoon JY, Kim TS. Remifentanil promotes osteoblastogenesis by upregulating Runx2/osterix expression in preosteoblastic C2C12 cells. J Dent Anesth Pain Med 2019;19:91-9.

12. Jeon HO, Choi IS. Effect of remifentanil on pre-osteoclast cell differentiation in vitro. 2018;18(1):9-17.

13. Baik SW, Park BS, Kim YH, et al. Effects of Remifentanil Preconditioning on Osteoblasts under HypoxiaReoxygenation Condition. Int J Med Sci 2015;12:583-9.

14. Chechik O, Arbel R, Salai M, et al. Opiates do not violate the viability and proliferative activity of human articular chondrocytes. Cell Tissue Bank 2014;15:391-5.

15. Quinn TM, Grodzinsky AJ, Hunziker EB, et al. Effects of injurious compression on matrix turnover around individual cells in calf articular cartilage explants. J Orthop 
Res 1998;16:490-9.

16. Huang JG, Xia C, Zheng X, et al. 17 $\beta$-Estradiol promotes cell proliferation in rat osteoarthritis model chondrocytes via PI3K/Akt pathway. Cell Mol Biol Lett 2011;16:564-75.

17. Sugimori K, Matsui K, Motomura H, et al. BMP-2 prevents apoptosis of the N1511 chondrocytic cell line through PI3K/Akt-mediated NF-kappaB activation. J Bone Miner Metab 2005;23:411-9.

18. Ikegami D, Akiyama H, Suzuki A, et al. Sox9 sustains chondrocyte survival and hypertrophy in part through Pik3ca-Akt pathways. Development 2011;138:1507-19.

19. Prasadam I, Crawford R, Xiao Y. Aggravation of ADAMTS and matrix metalloproteinase production and role of ERK1/2 pathway in the interaction of osteoarthritic subchondral bone osteoblasts and articular cartilage chondrocytes -- possible pathogenic role in osteoarthritis. J Rheumatol 2012;39:621-34.

20. Wang Q, Zhou X, Yang L, et al. Gentiopicroside (GENT) protects against sepsis induced by lipopolysaccharide (LPS) through the NF-kappaB signaling pathway. Ann Transl Med 2019;7:731.

21. Liu S, Cao C, Zhang Y, et al. PI3K/Akt inhibitor partly decreases TNF- $\alpha$-induced activation of fibroblastlike synoviocytes in osteoarthritis. J Orthop Surg Res 2019;14:425.

22. Xue JF, Shi ZM, Zou J, et al. Inhibition of PI3K/ AKT/mTOR signaling pathway promotes autophagy of articular chondrocytes and attenuates inflammatory response in rats with osteoarthritis. Biomed Pharmacother 2017;89:1252-61.

23. Rigoglou S, Papavassiliou AG. The NF-кB signalling pathway in osteoarthritis. Int J Biochem Cell Biol 2013;45:2580-4.

24. Chen J, Crawford R, Xiao Y. Vertical inhibition of the PI3K/Akt/mTOR pathway for the treatment of osteoarthritis. J Cell Biochem 2013;114:245-9.

25. Wang C, Zeng L, Zhang T, et al. Tenuigenin Prevents IL-1beta-induced Inflammation in Human Osteoarthritis Chondrocytes by Suppressing PI3K/AKT/NF-kappaB Signaling Pathway. Inflammation 2016;39:807-12.

26. Qian YQ, Feng ZH, Li XB, et al. Downregulating PI3K/ $\mathrm{Akt} / \mathrm{NF}-\kappa \mathrm{B}$ signaling with allicin for ameliorating the progression of osteoarthritis: in vitro and vivo studies. Food Funct 2018;9:4865-75.

27. Xie L, Xie H, Chen C, et al. Inhibiting the PI3K/AKT/ $\mathrm{NF}-\kappa \mathrm{B}$ signal pathway with nobiletin for attenuating the development of osteoarthritis: in vitro and in vivo studies. Food Funct 2019;10:2161-75.
28. Rogart JN, Barrach HJ, Chichester CO. Articular collagen degradation in the Hulth-Telhag model of osteoarthritis. Osteoarthritis Cartilage 1999;7:539-47.

29. Huang X, Chen Z. TMF inhibits miR-29a/Wnt/ $\beta$-catenin signaling through upregulating Foxo3a activity in osteoarthritis chondrocytes. Drug Des Devel Ther 2019;13:2009-19.

30. Grodzinsky AJ, Wang Y, Kakar S, et al. Intra-articular dexamethasone to inhibit the development of posttraumatic osteoarthritis. J Orthop Res 2017;35:406-11.

31. Mahjoub M, Berenbaum F, Houard X. Why subchondral bone in osteoarthritis? The importance of the cartilage bone interface in osteoarthritis. Osteoporos Int 2012;23 Suppl 8:S841-6.

32. Wang C, Liao H, Cao Z. Role of Osterix and MicroRNAs in Bone Formation and Tooth Development. Med Sci Monit 2016;22:2934-42.

33. Nakashima K, Zhou X, Kunkel G, et al. The novel zinc finger-containing transcription factor osterix is required for osteoblast differentiation and bone formation. Cell 2002;108:17-29.

34. Pullig O, Weseloh G, Ronneberger D, et al. Chondrocyte differentiation in human osteoarthritis: expression of osteocalcin in normal and osteoarthritic cartilage and bone. Calcif Tissue Int 2000;67:230-40.

35. Ducy P, Desbois C, Boyce B, et al. Increased bone formation in osteocalcin-deficient mice. Nature 1996;382:448-52.

36. Pitsillides AA, Beier F. Cartilage biology in osteoarthritis-lessons from developmental biology. Nat Rev Rheumatol 2011;7:654-63.

37. Hulejová H, Baresova V, Klezl Z, et al. Increased level of cytokines and matrix metalloproteinases in osteoarthritic subchondral bone. Cytokine 2007;38:151-6.

38. Malemud CJ. Matrix metalloproteinases (MMPs) in health and disease: an overview. Front Biosci 2006;11:1696-701.

39. Andersen TL, del Carmen Ovejero M, Kirkegaard T, et al. A scrutiny of matrix metalloproteinases in osteoclasts: evidence for heterogeneity and for the presence of MMPs synthesized by other cells. Bone 2004;35:1107-19.

40. Billinghurst RC, Dahlberg L, Ionescu M, et al. Enhanced cleavage of type II collagen by collagenases in osteoarthritic articular cartilage. J Clin Invest 1997;99:1534-45.

41. Knäuper V, Bailey L, Worley JR, et al. Cellular activation of proMMP-13 by MT1-MMP depends on the C-terminal domain of MMP-13. FEBS Lett 2002;532:127-30.

42. Litherland GJ, Dixon C, Lakey RL, et al. Synergistic collagenase expression and cartilage collagenolysis are 
phosphatidylinositol 3-kinase/Akt signaling-dependent. J Biol Chem 2008;283:14221-9.

43. Shakibaei M, John T, Schulze-Tanzil G, et al. Suppression of NF-kappaB activation by curcumin leads to inhibition of expression of cyclo-oxygenase- 2 and matrix metalloproteinase-9 in human articular chondrocytes: Implications for the treatment of osteoarthritis. Biochem Pharmacol 2007;73:1434-45.

44. Chen H, Wu G, Sun Q, et al. Hyperbaric oxygen protects mandibular condylar chondrocytes from interleukin-1betainduced apoptosis via the PI3K/AKT signaling pathway. Am J Transl Res 2016;8:5108-17.

45. Bai C, Yang X, Zou K, et al. Anti-proliferative effect of RCE-4 from Reineckia carnea on human cervical cancer HeLa cells by inhibiting the PI3K/Akt/mTOR signaling pathway and NF-kappaB activation. Naunyn Schmiedebergs Arch Pharmacol 2016;389:573-84.

46. Schulze-Tanzil G, Mobasheri A, Sendzik J, et al. Effects of curcumin (diferuloylmethane) on nuclear factor kappaB signaling in interleukin-1beta-stimulated chondrocytes. Ann N Y Acad Sci 2004;1030:578-86.

47. Jiao Y, Ma X, Zhang Z. Interleukin-1 increase nitric oxide synthesis through up-regulation of inducible nitric-oxide synthase by rabbit mandibular condylar cartilage cells in vitro. Zhonghua Kou Qiang Yi Xue Za Zhi 2001;36:345-7.

48. Goodlad RA. Quantification of epithelial cell proliferation, cell dynamics, and cell kinetics in vivo. Wiley interdisciplinary reviews. Wiley Interdiscip Rev Dev Biol 2017. doi: 10.1002/wdev.274.

49. Huang X, Lyu J. Tumor suppressor function of miR-483$3 p$ on breast cancer via targeting of the cyclin E1 gene. Exp Ther Med 2018;16:2615-20.

50. Zhang XH, Xu XX, Xu T. Ginsenoside Ro suppresses interleukin-1beta-induced apoptosis and inflammation in rat chondrocytes by inhibiting NF-kappaB. Chin J Nat

Cite this article as: $\mathrm{Ke} \mathrm{H}$, Mou X, Xia Q. Remifentanil repairs cartilage damage and reduces the degradation of cartilage matrix in post-traumatic osteoarthritis, and inhibits IL- $1 \beta$-induced apoptosis of articular chondrocytes via inhibition of PI3K/ AKT/NF-кB phosphorylation. Ann Transl Med 2020;8(22):1487. doi: $10.21037 / \mathrm{atm}-20-6000$
Med 2015;13:283-9.

51. Wang JJ, Huan SK, Hsieh KH, et al. Inhibitory effect of midazolam on MMP-9, MMP-1 and MMP-13 expression in PMA-stimulated human chondrocytes via recovery of NF-kappaB signaling. Arch Med Sci 2013;9:332-9.

52. Chen C, Ma C, Zhang Y, et al. Pioglitazone inhibits advanced glycation end product-induced TNF-alpha and MMP-13 expression via the antagonism of NF-kappaB activation in chondrocytes. Pharmacology 2014;94:265-72.

53. Lei S, Su W. Hyperglycemia-Induced Oxidative Stress Abrogates Remifentanil Preconditioning-Mediated Cardioprotection in Diabetic Rats by Impairing Caveolin3-Modulated PI3K/Akt and JAK2/STAT3 Signaling. Oxid Med Cell Longev 2019;2019:9836302.

54. Dou MY, Wu H, Zhu HJ, et al. Remifentanil preconditioning protects rat cardiomyocytes against hypoxia-reoxygenation injury via $\delta$-opioid receptor mediated activation of PI3K/Akt and ERK pathways. Eur J Pharmacol 2016;789:395-401.

55. $\mathrm{Hu} \mathrm{X}, \mathrm{Xie} \mathrm{C}, \mathrm{He} \mathrm{S}$, et al. Remifentanil postconditioning improves global cerebral ischemia-induced spatial learning and memory deficit in rats via inhibition of neuronal apoptosis through the PI3K signaling pathway. Neurol Sci 2013;34:1955-62.

56. Zhang Y, Du Z, Zhou Q, et al. Remifentanil attenuates lipopolysaccharide-induced acute lung injury by downregulating the NF- $\mathrm{BB}$ signaling pathway. Inflammation 2014;37:1654-60.

57. Zhang JN, Ma Y, Wei XY, et al. Remifentanil Protects against Lipopolysaccharide-Induced Inflammation through PARP-1/NF- $\kappa$ B Signaling Pathway. Mediators Inflamm 2019;2019:3013716.

(English Language Editor: A. Kassem) 